\title{
In-Situ XAFS Study of Ag Clusters in Zeolite 4A
}

\author{
Y. Suzuki $^{1}$, T. Miyanaga ${ }^{* 1}$, H. Hoshino ${ }^{2}$, N. Matsumoto ${ }^{1}$ and T. Ainai ${ }^{2}$ \\ ${ }^{1}$ Faculty of Science and Technology, Hirosaki University, Hirosaki, Aomori 036-8561, Japan \\ ${ }^{2}$ Faculty of Education, Hirosaki University, Hirosaki, Aomori 036-8560, Japan
}

Received June 26, 2003; accepted in revised form April 5, 2004

PACS number: $03.30+\mathrm{p}$

\begin{abstract}
In-situ Ag K-edge XAFS measurements have been carried out for fully $\mathrm{Ag}^{+}$exchanged zeolite $4 \mathrm{~A}(\mathrm{Ag}-4 \mathrm{~A})$ during continuous dehydration under vacuum in the temperature range between room temperature (r.t.) and $300^{\circ} \mathrm{C}$. The structural parameters (distance $r$, coordination number $N$ and root mean square displacement $\sigma$ ) were derived by a three-shell (short and long Ag-O contacts and Ag-Ag contact) by curve-fitting analysis. The systematic dehydration effect on the structural change in the Ag clusters is studied by in-situ XAFS experiments. $\mathrm{Ag}^{+}$ions are reduced by removal of water molecules due to evacuation for 20 minutes at r.t. The formation of Ag clusters is suggested by full evacuation at r.t. With increasing dehydration temperature, $N$ of $\mathrm{Ag}$ around a central $\mathrm{Ag}$ increases. For the $\mathrm{Ag}$ cluster formed at $300^{\circ} \mathrm{C}$ the $\mathrm{Ag}$ - $\mathrm{Ag}$ contact distance is evaluated to be $2.79 \pm 0.02 \AA$ and $N$ of $\mathrm{Ag}$ around a central $\mathrm{Ag}$ is $4.1 \pm 0.3$. The cluster formation is supported by XANES spectra which show that the $\mathrm{Ag}^{+}$ions in the fully hydrated $\mathrm{Ag}-4 \mathrm{~A}$ change to $\mathrm{Ag}$ atoms in the dehydrated $\mathrm{Ag}-4 \mathrm{~A}$ at $300^{\circ} \mathrm{C}$ under vacuum.
\end{abstract}

\section{Introduction}

In the fully $\mathrm{Ag}^{+}$-exchanged $4 \mathrm{~A}(\mathrm{Ag}-4 \mathrm{~A})$ the $12 \mathrm{Ag}^{+}$ions are present inside zeolite cages, as needed to balance the anionic charge of the zeolite framework. The white color of the hydrated Ag-4A changes through yellow to brown by heating up to $400^{\circ} \mathrm{C}$ under vacuum [1]. These changes in color by heating under vacuum are related to the formation of silver clusters due to the interaction of the silver atoms produced by reduction of $\mathrm{Ag}^{+}$ions during dehydration with the other silver atoms or $\mathrm{Ag}^{+}$ions [2]. $\mathrm{X}$-ray diffraction experiments of the zeolite single crystal [3, 4] and EXAFS measurements on powder [5,6] suggest the presence of the silver cluster in the zeolite cage. Recently it was found that the color of the white Ag-4A changes into pale yellow by full dehydration under vacuum at $27^{\circ} \mathrm{C}$ for 7 hours [7]. It is interesting to study the changes in the local structure of the silver cluster for the same Ag-4A zeolite by heating at different temperatures under continuous evacuation. For this purpose an in-situ XAFS measurement was carried out using a special chamber [8] where the evacuation and heating are operated simultaneously. In this paper, we report results of in-situ EXAFS measurements on the $\mathrm{Ag} \mathrm{K}$-edge for the fully $\mathrm{Ag}^{+}$-exchanged $\mathrm{Ag}-4 \mathrm{~A}$ powder sample by continuous evacuation at room temperature (r.t.) and heating under vacuum, respectively.

\section{Experimental and data analyses}

Fully $\mathrm{Ag}^{+}$-exchanged $4 \mathrm{~A}(\mathrm{Ag}-4 \mathrm{~A})$ powder samples were prepared by immersing $\mathrm{Na}-4 \mathrm{~A}\left(\mathrm{Na}_{12}\left[\left(\mathrm{AlO}_{2}\right)_{12}\left(\mathrm{SiO}_{2}\right)_{12}\right] 27.5 \mathrm{H}_{2} \mathrm{O}\right)$ zeolite in an aqueous $\mathrm{AgNO}_{3}$ solution at $25^{\circ} \mathrm{C}$. The details of the sample preparation are described elsewhere $[4,6]$. The white Ag-4A powder (fully hydrated) sample was packed in the cell. The cell was mounted in the in-situ XAFS measurement chamber. By

*e-mail: takaf@cc.hirosaki-u.ac.jp holding the sample in the chamber XAFS measurements were carried out (1) under continuous evacuation at r.t. and (2) heating up to $300^{\circ} \mathrm{C}$ under vacuum $\left(\sim 10^{-3} \mathrm{~Pa}\right)$ [8]. Ag K-edge X-ray absorption spectra were obtained at beamline BL-10B of the Photon Factory in KEK. A Si(311) channel-cut monochrometer was used, and energy and current of the storage ring were $3.0 \mathrm{GeV}$ and $250 \sim 400 \mathrm{~mA}$, respectively. EXAFS spectra were recorded in transmission mode using ionization chamber detectors. The EXAFS interference function extracted from the absorption spectra was Fourier transformed by XANADU code [9]. In order to obtain the structural parameters, the EXAFS function was fitted by a non-linear least-squares method. The non-linear least square fitting method was applied to the experimental data as described below:

$$
\begin{aligned}
\chi(k)= & \sum_{j} \frac{S_{0}^{2} N_{j}}{k r_{j}^{2}} f_{j}\left(k, r_{j}\right) \exp \left(-2 \sigma_{j}^{2} k^{2}\right) \\
& \times \exp \left(-2 r_{j} / \lambda(k)\right) \sin \left[2 k r_{j}+\varphi_{j}(k)\right]
\end{aligned}
$$

where $r, N$ and $\sigma$ are interatomic distance, coordination number and root mean square displacement, respectively, for each atomic pair. Phase shift $\varphi(k)$, backscattering amplitude $f(k, r)$ and electron mean free path $\lambda(k)$ are obtained from FEFF6.01 calculation [10]. The $k$-range for the curve-fitting method was $3.0 \sim 11.5 \AA^{-1}$. Ag foil and $\mathrm{AgNO}_{3}$ were used as standard samples for energy correction. In the present analyses, the multiplescattering effect was neglected.

\section{Results}

Figure 1(a) shows the changes of $k \chi(k)$ EXAFS spectra obtained for Ag-4A during continuous evacuation from 0 to 20 minutes at r.t. In these experiments the sample was evacuated from $0.1 \mathrm{MPa}$ to $\sim 10^{-3} \mathrm{~Pa}$ and the EXAFS spectra were recorded continuously for 2 minutes per one scan. It is found that at the evacuation for 20 minutes a few water molecules are removed from the unit zeolite cage [7]. The EXAFS spectra at the evacuation for 20 minutes were the same as those at the fully dehydrated condition after 7 hours. As seen in Fig. 1(a) $k \chi(k)$ profiles change clearly with increasing evacuation time. Especially the structure around $1 \sim 4 \AA^{-1}$ is changing as indicated by arrows in Fig. 1(a).

The corresponding change of Fourier transforms, $|\mathrm{FT}(r)|$, is shown in Fig. 1(b). With increasing evacuation time, the intensity of the first peak (around $2 \AA$ ) decreases, while the intensity of the second peak (around $3 \AA$ ) increases considerably. The first peak corresponds to short Ag-O contact and the second peak to long $\mathrm{Ag}-\mathrm{O}$ contact and $\mathrm{Ag}-\mathrm{Ag}$ contact, respectively $[5,6]$. As the evacuation proceeds, the positions of the first peak and the second peak shift to smaller $r$, which indicates that the contact 

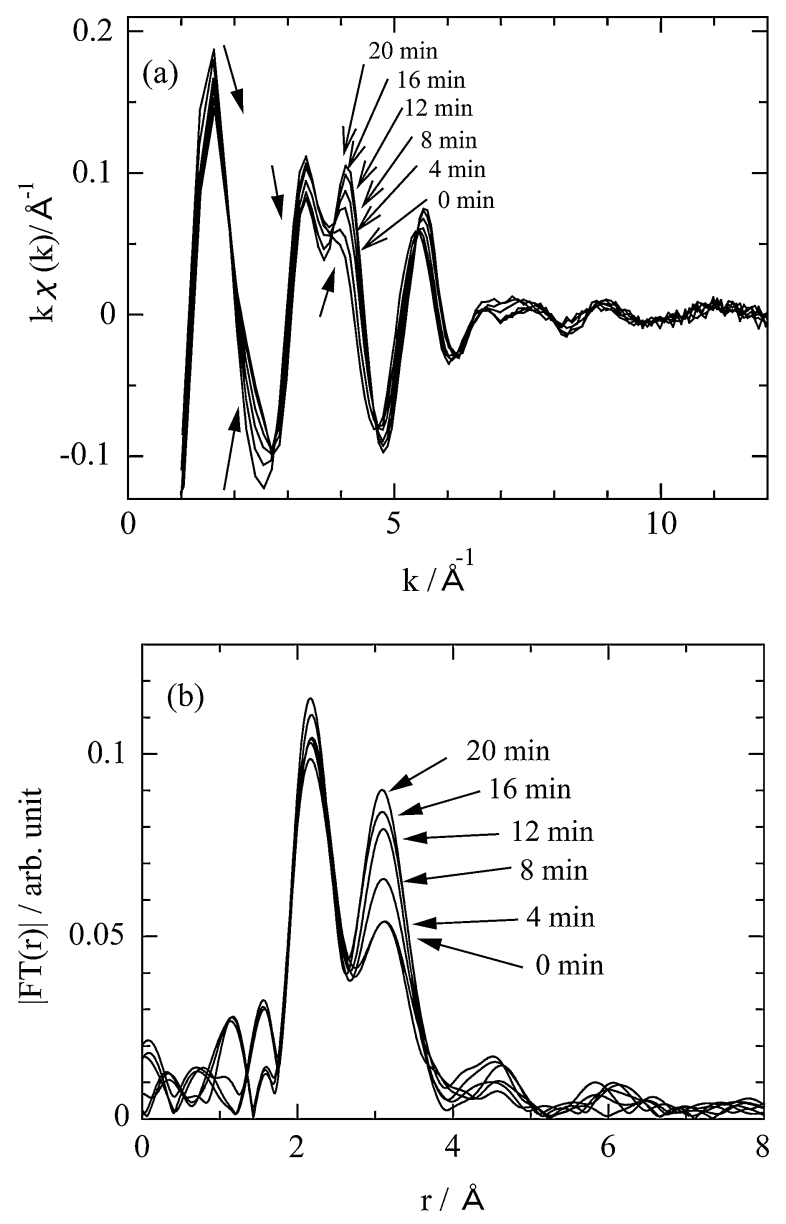

Fig. 1. Change of EXAFS $k \chi(k)$ spectra (a) and corresponding Fourier transform (b) for Ag-4A during evacuation as room temperature. The thick arrows indicate the change of evacuating time. The time interval for each spectrum is 4 minutes.

distances become short with increasing dehydration at r.t. It is interesting to point out that these changes in the contact distances for evacuation at r.t. are in qualitative agreement with those obtained for evacuation at high temperatures [6]. However, further analyses were not tried for the results obtained by 2 minutes per scan, because the quality of data was not high enough.

Figure 2(a) shows the changes of $k \chi(k)$ EXAFS spectra of the same Ag-4A sample obtained by scanning for more than 20 minutes. All spectra were measured at room temperature. The quality of data is good for further analyses. The curve represented by "A. $0.1 \mathrm{MPa}$ " corresponds to the condition at $0.1 \mathrm{MPa}$ and r.t. (Before evacuation and fully hydrated), "B. full evac." to full evacuation at r.t., "C. after $100^{\circ} \mathrm{C}$ " to heating up to $100^{\circ} \mathrm{C}$ under vacuum, "D. after $200^{\circ} \mathrm{C}$ " to heating up to $200^{\circ} \mathrm{C}$ under vacuum and "E. after $300^{\circ} \mathrm{C}$ " to heating up to $300^{\circ} \mathrm{C}$ under vacuum. In the $k \chi(k)$ curve for the fully hydrated $\mathrm{Ag}-4 \mathrm{~A}$ (sample $\mathrm{A}$ ) there appear a peak around $3.2 \AA^{-1}$ and a shoulder around $4 \AA^{-1}$. After full evacuation at r.t. (sample $B$ ) the shoulder disappears and two peaks appear around 3 and $4 \AA^{-1}$. By further heating under vacuum up to $300^{\circ} \mathrm{C}$ (samples $\mathrm{C}, \mathrm{D}$ and $\mathrm{E}$ ) the dip between two peaks becomes deeper.

Figure 2(b) shows the corresponding changes of $|\mathrm{FT}(r)|$. Two peaks appear around $2 \AA$ and $3 \AA$. From $A$ to $E$ the intensities of the second peak (around $3 \AA$ ) increase, then the ratio of the intensity of the second peak to that of the first peak becomes large. The positions of the first and second peaks shift to smaller $r$ from A to E.
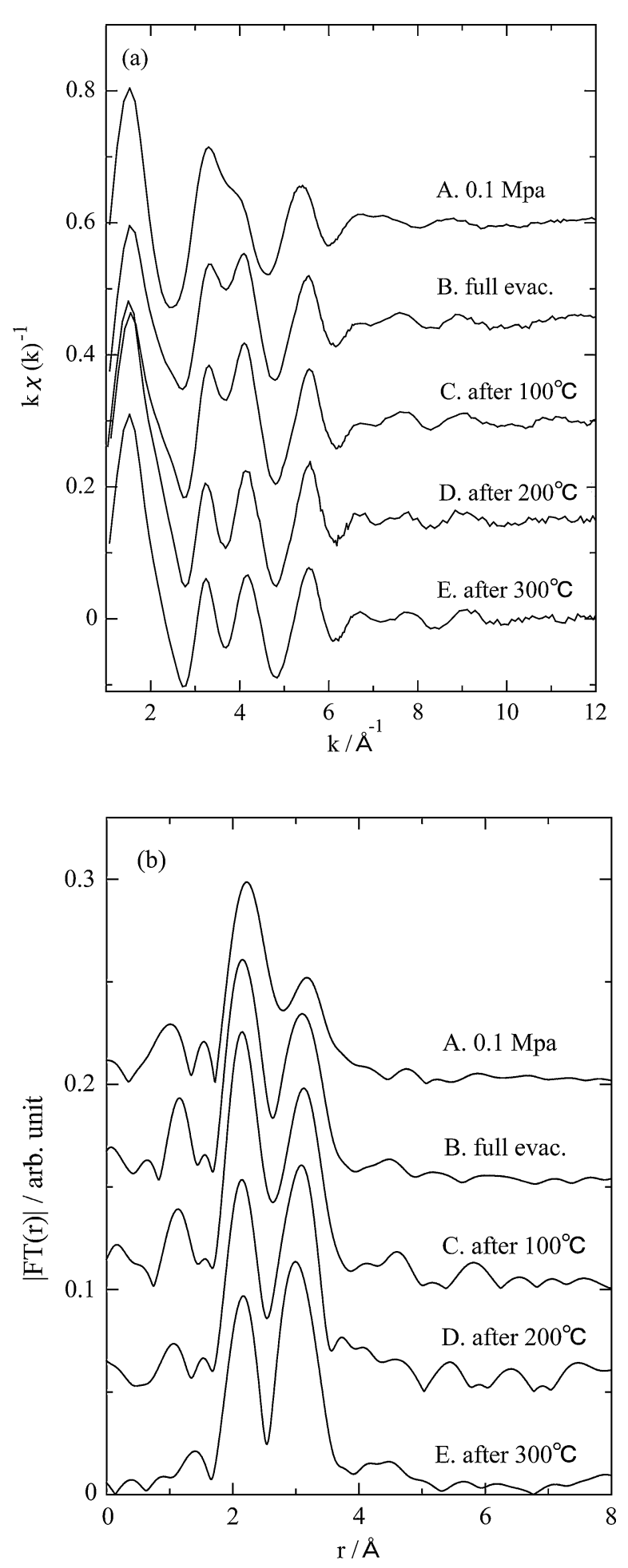

Fig. 2. Ag K-edge EXAFS $k \chi(k)$ spectra (a) and corresponding Fourier transform (b) for Ag-4A measured at r.t. A. measured at r.t. $0.1 \mathrm{MPa}$, B. measured at r.t. full evacuated, C. measured at r.t. after heating to $100^{\circ} \mathrm{C}$ in vacuum, D. heating to $200^{\circ} \mathrm{C}$ and $\mathrm{E}$. heating to $300^{\circ} \mathrm{C}$.

\section{Discussion}

In order to derive the structural parameters, three-shell curve fitting analyses were carried out in the same way as in the previous work [6]: The three-shell model consists of two Ag-O contacts (short and long contact distances) and one Ag-Ag contact. An example of the fitting quality is shown in Fig. 3 for sample E. The fitting is fairly good. When the fitting was made by using the Ag-Si distance instead of the long Ag-O distance, the fitting quality was quite bad. The structural parameters obtained from the present 


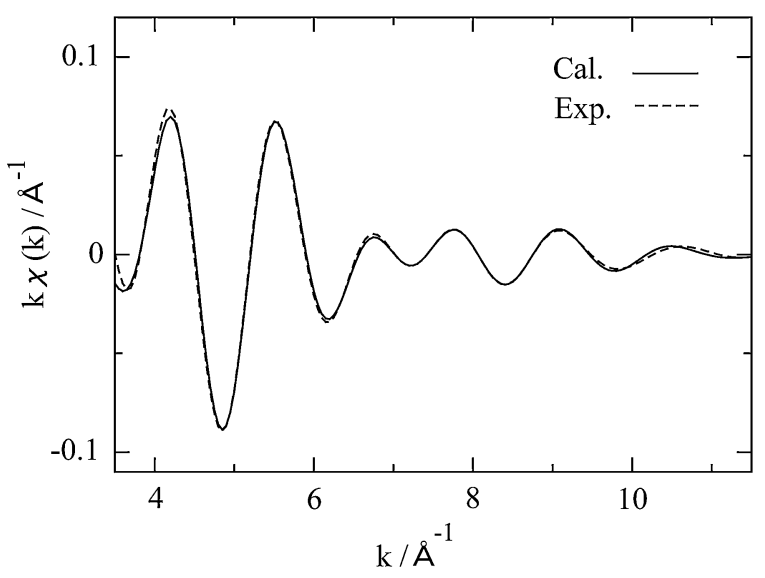

Fig. 3. Comparison for the Ag-K-edge EXAFS $k \chi(k)$ between experimental curve and calculated curve obtained by curve-fitting for the sample B.

Table I. Structural parameters ( $r$ : contact distance, $N$ : coordination number and $\sigma$ : root mean square displacement) for Ag- 4 A.

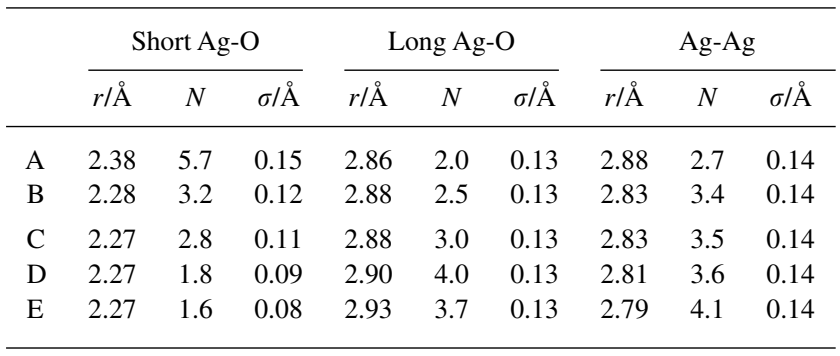

EXAFS spectra are summarized in Table I. Figure 4 shows the contribution from each shell in $r$-space (Fourier transform) as an example for sample $\mathrm{E}$.

There are $\mathrm{Ag}^{+}$ions in the fully hydrated $\mathrm{Ag}-4 \mathrm{~A}$ at $0.1 \mathrm{MPa}$ and r.t. The short Ag-O distance decreases from $2.38 \pm 0.02 \AA$ (sample A) to $2.28 \pm 0.02 \AA$ (sample B) due to evacuation at r.t. The coordination number $(N)$ of $\mathrm{O}$ around a central $\mathrm{Ag}^{+}$ decreases from $5.7 \pm 0.5$ (sample A) to $3.2 \pm 0.5$ (sample B). In the fully hydrated $\mathrm{Ag}-4 \mathrm{~A}$ there are water molecules in the vicinity of the $\mathrm{Ag}^{+}$ions. In common state, $\mathrm{Ag}^{+}$complex has tetrahedrally coordinated structure, for example, $\mathrm{Ag}\left(\mathrm{H}_{2} \mathrm{O}\right)_{4}{ }^{+}$in aqueous solution [11], and the interatomic distance is reported to about $2.35-42 \AA$. On the other hand, in the distorted state,

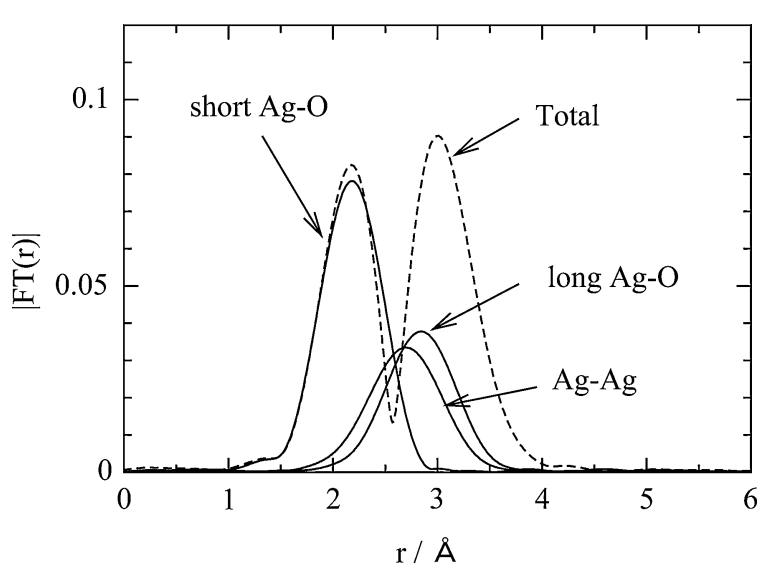

Fig. 4. Contributions from each shell (short Ag-O, long Ag-O, Ag-Ag, solid lines) in $r$-space (FT) for sample E. Dashed line is the FT from the total contribution.
5 or 6 coordinated complexes are reported [12] and the $\mathrm{Ag}^{+}$ complex is expected to be distorted in the zeolite cavity. The large root mean square displacement $\sigma$ of 0.15 shows the existence of distortion around the central $\mathrm{Ag}^{+}$ion and the coordination number of 5.7 includes the contributions from $\mathrm{Ag}-\left(\mathrm{OH}_{2}\right)$ and $\mathrm{Ag}-$ $\mathrm{O}$ (zeolite cage). Therefore the interatomic distance of $2.38 \AA$ is an average value for the widely distributed $\mathrm{Ag}-\mathrm{O}$ pairs. By evacuation the water molecules are removed, then $N$ of $\mathrm{O}$ around a central $\mathrm{Ag}^{+}$decreases. Since the $\mathrm{Ag}^{+}$ions in sample A have contact with oxygens in the zeolite framework and of water molecules, the interaction between the $\mathrm{Ag}^{+}$ion and the framework oxygen becomes strong by removal of water molecules, which results in a reduction of the short Ag-O contact distance. For the Ag$\mathrm{Ag}$ contact the contact distance decreases from $2.88 \pm 0.02 \AA$ (sample A) to $2.83 \pm 0.02 \AA$ (sample B) and $N$ of $\mathrm{Ag}^{+}$around a central $\mathrm{Ag}^{+}$increases from $2.7 \pm 0.2$ (sample A) to $3.4 \pm$ 0.2 (sample B). The slight reduction of the distance and slight increment of $N$ for the $\mathrm{Ag}-\mathrm{Ag}$ contact by dehydration suggest that the $\mathrm{Ag}^{+}$ions are partly reduced to $\mathrm{Ag}$ atom by the removal of water molecules, since the Coulomb repulsion becomes weak when one of the $\mathrm{Ag}^{+}$ions is reduced to $\mathrm{Ag}$ atom between $\mathrm{Ag}^{+}$ ions. For the long Ag-O contact the contact distance increases from $2.86 \pm 0.02 \AA$ (sample A) to $2.88 \pm 0.02 \AA$ (sample B) and $N$ of $\mathrm{O}$ around a central $\mathrm{Ag}^{+}$increases from $2.0 \pm 0.2$ (sample $\mathrm{A}$ ) to $2.5 \pm 0.2$ (sample B). It is noted that the appearance of Ag atoms produced by removal of water molecules makes the long Ag-O contact distance slightly longer due to an increase of the repulsive interaction. It is interesting to note that the partial reduction of the $\mathrm{Ag}^{+}$ions occur due to the removal of water molecules from the zeolite cages by full dehydration under vacuum at r.t., which results in the coloration of white $\mathrm{Ag}-4 \mathrm{~A}$ at $27^{\circ} \mathrm{C}$ [7] and the complete removal of water molecules has been confirmed by IR study of Ag-4A [8].

For sample $\mathrm{C}$ to $\mathrm{E}$ the effect of the dehydration on the $\mathrm{Ag}$ 4A sample at high temperatures between 100 and $300^{\circ} \mathrm{C}$ under vacuum is discussed. The short Ag-O contact distance remains at $2.27 \pm 0.02 \AA$ independent of temperature, while the $N$ of $\mathrm{O}$ around a central $\mathrm{Ag}$ decreases from $2.8 \pm 0.3$ at $100^{\circ} \mathrm{C}$ to 1.6 \pm 0.3 at $300^{\circ} \mathrm{C}$, which arises from the increase of dehydration with increasing temperature under vacuum. This suggests that the reduction of the $\mathrm{Ag}^{+}$ion in the short $\mathrm{Ag}-\mathrm{O}$ contact does not proceed at higher temperature. It is noted that, the distance of $2.27 \AA$ for Ag-O is close to the value for linear or two-fold complex. The Ag-Ag contact distance decreases from $2.83 \pm$ $0.02 \AA$ at $100^{\circ} \mathrm{C}$ to $2.79 \pm 0.02 \AA$ at $300^{\circ} \mathrm{C}$ and the $N$ of $\mathrm{Ag}$ around a central $\mathrm{Ag}$ increases from $3.5 \pm 0.3$ at $100^{\circ} \mathrm{C}$ to $4.1 \pm$ 0.3 at $300^{\circ} \mathrm{C}$. With increasing temperature the reduction of the $\mathrm{Ag}^{+}$ions proceed and the diffusion of the $\mathrm{Ag}$ atoms or $\mathrm{Ag}^{+}$ions is accelerated, which results in a decrease in the bond distance due to weaker repulsive interaction between $\mathrm{Ag}^{+}$ions and $\mathrm{Ag}$ atoms and the increase in the coordination number. For the long $\mathrm{Ag}-\mathrm{O}$ contact the distance increases from $2.88 \pm 0.02 \AA$ at $100^{\circ} \mathrm{C}$ to $2.93 \pm 0.02 \AA$ at $300^{\circ} \mathrm{C}$ and the $N$ of $\mathrm{O}$ around a central $\mathrm{Ag}$ increases from $3.0 \pm 0.3$ at $100^{\circ} \mathrm{C}$ to $3.7 \pm 0.3$ at $300^{\circ} \mathrm{C}$. As the reduction of $\mathrm{Ag}^{+}$ion proceeds, the repulsion between $\mathrm{Ag}$ and the frame oxygen increases. This results in an increase of the long Ag$\mathrm{O}$ distance. It is suggested that the contribution of the $\mathrm{Ag}$ atoms become dominant for the $\mathrm{Ag}-\mathrm{Ag}$ and the long $\mathrm{Ag}-\mathrm{O}$ contacts at high temperature [6].

The root mean square displacement $\sigma$ for the short Ag-O contact decreases with increasing dehydration, while for the long $\mathrm{Ag}-\mathrm{O}$ and $\mathrm{Ag}-\mathrm{Ag}$ contacts $\sigma$ remains unchanged. 


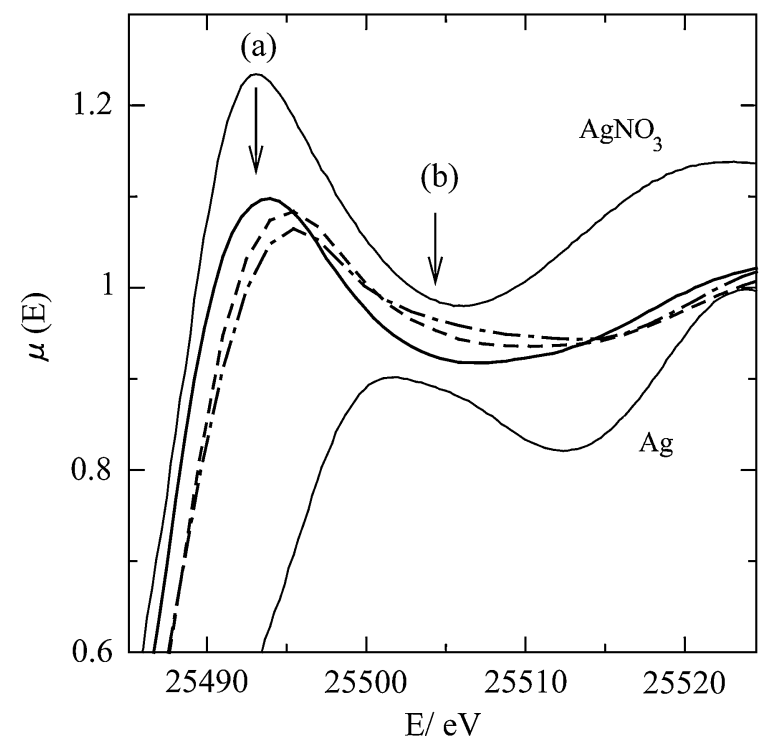

Fig. 5. XANES spectra of the Ag K-edge for Ag-4A: Solid line presents the result of sample A, dashed line does that of sample B, dot-dashed line does sample E. For comparison XANES's of $\mathrm{AgNO}_{3}(\mu(E)$ is shifted to +0.1) and $\mathrm{Ag}(\mu(E)$ is shifted to -0.1$)$ are also presented by thin solid line.

The fact that the coordination number $N$ of $\mathrm{Ag}$ around a central $\mathrm{Ag}$ increases from $3.4 \pm 0.3$ for the $\mathrm{Ag}-4 \mathrm{~A}$ fully evacuated at r.t. through $3.6 \pm 0.3$ at $200^{\circ} \mathrm{C}$ to $4.1 \pm 0.3$ at $300^{\circ} \mathrm{C}$ and the $\mathrm{Ag}-\mathrm{Ag}$ contact distance decreases from $2.83 \pm 0.02 \AA$ for the evacuated sample at r.t. through $2.81 \pm 0.02 \AA$ at $200^{\circ} \mathrm{C}$ to $2.79 \pm 0.02 \AA$ at $300^{\circ} \mathrm{C}$ indicates that the formation of $\mathrm{Ag}$ clusters [3-7] in the zeolites cages sets on by dehydration under vacuum at r.t. and is accelerated by heating. The present systematic results for distance, coordination number and root mean square displacement are obtained for the first time by carrying out in-situ EXAFS experiments.

Figure 5 shows the changes of X-ray absorption near edge structure (XANES) for samples A, B and E. For comparison, XANES spectra of $\mathrm{AgNO}_{3}$ and $\mathrm{Ag}$ foil are shown together. The XANES spectrum for sample A fully hydrated Ag-4A at r.t. is similar to that of $\mathrm{AgNO}_{3}$ which is typical for the compounds with $\mathrm{Ag}^{+}-\mathrm{O}$ pair. The peak (a) of the XANES spectra for samples B fully evacuated at r.t. and sample $E$ heated to $300{ }^{\circ} \mathrm{C}$ under vacuum shift to higher energy and the intensity of the peak decreases with increasing dehydration. On the other hand, the intensity around the minimum (b) of XANES spectra for samples B and E increases with increasing temperature, which suggests the reduction of the valence state of the X-ray absorber from $\mathrm{Ag}^{+}$ions to $\mathrm{Ag}$ atom as indicated by XANES spectra of Ag foil. This behavior of the XANES spectra indicates that the $\mathrm{Ag}^{+}$ions in the hydrated $\mathrm{Ag}-4 \mathrm{~A}$ is reduced to $\mathrm{Ag}$ atoms in the $\mathrm{Ag}-4 \mathrm{~A}$ heated at $300^{\circ} \mathrm{C}$, which supports the formation of the Ag clusters with increasing dehydration temperature as we discussed on the EXAFS results.

\section{Conclusion}

The in-situ Ag K-edge EXAFS measurements have been carried out for fully $\mathrm{Ag}^{+}$-exchanged zeolite $4 \mathrm{~A}(\mathrm{Ag}-4 \mathrm{~A})$ during continuous dehydration under vacuum in the temperature range between r.t. and $300^{\circ} \mathrm{C}$. The structural parameters (distance $r$, coordination number $N$ and root mean square displacement) were derived by a three-shell (short and long Ag-O contacts and AgAg contact) by curve-fitting analysis. The systematic dehydration effect on the structural change in the Ag clusters is discussed for the first time by carrying out the in-situ EXAFS experiments. It is found that the $\mathrm{Ag}^{+}$ions are reduced by removal of water molecules due to evacuation for 20 minutes. The formation of Ag clusters is suggested by full evacuation at r.t. With increasing dehydration temperature $N$ of $\mathrm{Ag}$ around a central $\mathrm{Ag}$ increases. For the $\mathrm{Ag}$ cluster formed at $300^{\circ} \mathrm{C}$ the $\mathrm{Ag}$ - $\mathrm{Ag}$ contact distance is evaluated to be $2.79 \pm 0.02 \AA$ and $N$ of $\mathrm{Ag}$ around a central $\mathrm{Ag}$ of $4.1 \pm 0.3$. The cluster formation is supported by the XANES spectra which show that the $\mathrm{Ag}^{+}$ion in the fully hydrated $\mathrm{Ag}$ $4 \mathrm{~A}$ change to $\mathrm{Ag}$ atoms in the dehydrated $\mathrm{Ag}-4 \mathrm{~A}$ at $300^{\circ} \mathrm{C}$ under vacuum.

Finally we should mention the limitation for the present analysis: our analysis is based on the three-shells model of short $\mathrm{Ag}-\mathrm{O}$, long $\mathrm{Ag}-\mathrm{O}$ and $\mathrm{Ag}-\mathrm{Ag}$ and the multiple scattering path was not taken into account. In our result the Ag coordination is indeed novel from the coordination chemistry point of view and a more sophisticated analysis using a later version of the theoretical EXAFS function (including the multiple scattering effect) will be needed to confirm the present results.

\section{Acknowledgements}

The synchrotron radiation experiments were performed at the Photon Factory in KEK under Proposal No. 2000G272 and 2002G279.

\section{References}

1. Hoshino, H., Bulletin of the Faculty of Education, Hirosaki University 75, 29 (1996).

2. Sun, T. and Seff, K., Chem. Rev. 94, 857 (1994).

3. Kim, Y. and Seff, K., J. Phys. Chem. 91, 668 (1987).

4. Gellens, L. R., Mortier, W. J. and Uytterhoeven, J. B., Zeolites 1, 11 (1981).

5. Miyanaga, T., Hoshino, H., Endo, H. and Sakane, H., J. Synchrotron Rad. 6, 442 (1999).

6. Miyanaga, T., Hoshino, H. and Endo, H., J. Synchrotron Rad. 8, 557 (2001).

7. Ainai, T., Master Thesis, Hirosaki University (2002).

8. Matsumoto, N., Master Thesis, Hirosaki University (2002).

9. Sakane, H. et al., Jpn. J. Appl. Phys. 32, 4641 (1993).

10. Zabinsky, S. I., Rehr, J. J., Ankudinov, A., Albers, R. C. and Eller, M. J., Phys. Rev. B 52, 2995 (1995).

11. Ohtaki, H. and Radnai, T., Chem. Rev. 93, 1157 (1993).

12. Cotton, F. A. and Wilkinson, G., "Advanced Inorganic Chemistry", 4th ed (1988). 